\title{
Simple Coiling versus Stent-Assisted Coiling of Paraclinoid Aneurysms : Radiological Outcome in a Single Center Study
}

\author{
Soo Yeon Kim, M.D.,' Dong Sun Park, M.D., ${ }^{1}$ Hye Yin Park, M.D., ${ }^{2}$ Young Il Chun, M.D., Ph.D., ${ }^{1}$ Chang Taek Moon, M.D., Ph.D., \\ Hong Gee Roh, M.D., Ph.D. ${ }^{3}$ \\ Departments of Neurosurgery, Radiology, Konkuk University Medical Center, Seoul, Korea \\ Institute of Environmental Medicine, '2 Seoul National University College of Medicine, Seoul, Korea
}

Objective : Paraclinoid aneurysms are a group of aneurysms arising at the distal internal carotid artery. Due to a high incidence of small, wide-necked aneurysms in this zone, it is often challenging to achieve complete occlusion when solely using detachable coils, thus stent placement is often required. In the present study, we aimed to investigate the effect of stent placement in endovascular treatment of paraclinoid aneurysms.

Methods : Data of 98 paraclinoid aneurysms treated by endovascular approach in our center from August 2005 to June 2016 were retrospectively reviewed. They were divided into two groups : simple coiling and stent-assisted coiling. Differences in the recurrence and progressive occlusion between the two groups were mainly analyzed. The recurrence was defined as more than one grade worsening according to Raymond-Roy Classification or major recanalization that is large enough to permit retreatment in the follow-up study compared to the immediate post-operative results.

Results : Complete occlusion was achieved immediately after endovascular treatment in eight out of 37 patients (21.6\%) in the stent-assisted group and 18 out of $61(29.5 \%)$ in the simple coiling group. In the follow-up imaging studies, the recurrence rate was lower in the stent-assisted group (one out of $37,2.7 \%)$ compared to the simple coiling group (13 out of $61,21.3 \%)(p=0.011)$. Multivariate logistic regression model showed lower recurrence rate in the stent-assisted group than the simple coiling group (odds ratio [OR] $0.051,95 \%$ confidence interval [CI] 0.005-0.527). Furthermore there was also a significant difference in the rate of progressive occlusion between the stent-assisted group (16 out of 29 patients, 55.2\%) and the simple coiling group (10 out of 43 patients, $23.3 \%)(p=0.006)$. The stent-assisted group also exhibited a higher rate of progressive occlusion than the simple coiling group in the multivariate logistic regression model (OR 3.208, 95\% Cl 1.106-9.302).

Conclusion : Use of stents results in good prognosis not only by reducing the recurrence rate but also by increasing the rate of progressive occlusion in wide-necked paraclinoid aneurysms. Stent-assisted coil embolization can be an important treatment strategy for paraclinoid aneurysms when considering the superiority of long term outcome.

Key Words : Intracranial aneurysm · Recurrence $\cdot$ Stents.

- Received : June 19, 2017 •Revised : August 17, 2017 •Accepted : September 25, 2017

- Address for reprints : Young II Chun, M.D., Ph.D.

Department of Neurosurgery, Konkuk University Medical Center, 120-1 Neungdong-ro, Gwangjin-gu, Seoul 05030, Korea

Tel : +82-2-2030-7357, Fax : +82-2-2030-7359, E-mail : youngil.chun@gmail.com

This is an Open Access article distributed under the terms of the Creative Commons Attribution Non-Commercial License (http://creativecommons.org/licenses/by-nc/4.0) which permits unrestricted non-commercial use, distribution, and reproduction in any medium, provided the original work is properly cited. 


\section{INTRODUCTION}

Paraclinoid aneurysms refer to lesions that derived from the internal carotid artery (ICA) between the distal dural ring and the posterior communicating arter ${ }^{26)}$. These include ventral ICA segments, carotid-ophthalmic segments, and ophthalmic segments. The surgical approach to paraclinoid aneurysms is often limited by the anterior clinoid process blocking the surgical corridor. In addition, excessive brain retraction can cause damage to the olfactory groove.

Therefore, endovascular embolization using coils is an important means of treating paraclinoid aneurysms. However, coil embolization is known to be associated with high recurrence compared to clipping with the recurrence rate ranging from $10 \%$ to $33.6 \%^{2,11,22)}$. Moreover, many paraclinoid aneurysms are small and wide-necked in morphology, and this often causes difficulty in achieving complete occlusion. Because partial occlusion of aneurysms was thought to be associated with high recurrence rates, coil embolization in paraclinoid aneurysms was often reinforced by stents in order to provide support for the otherwise unstable coil mass and to increase aneurysm neck coverage.

The authors conducted this study to review various aspects of coil embolization procedure on the paraclinoid aneurysms, and to compare the radiological outcomes depending on the use of stents.

\section{MATERIALS AND METHODS}

\section{Patient selection and data collection}

We retrospectively reviewed data of 113 paraclinoid ICA aneurysms among a total of 730 intracranial aneurysms treated by endovascular approach from August 2005 to June 2016 in our center. Of the 113 aneurysms, one large aneurysm treated with pipeline flow-diverting stents and 14 patients who had not been followed up by imaging after endovascular treatment were excluded. Nine aneurysms treated with balloon-assisted coil embolization were included in the simple coiling group. Finally, 98 paraclinoid aneurysms with 13 ruptured conditions were enrolled in this study, 37 lesions were treated with stent-assisted coiling and 61 lesions with simple coiling. Two neurointerventionalists participated in the treatment.

\section{Evaluation of clinical and radiological features}

Data on each patient's age, sex, aneurysm location, aneurysm projection, aneurysm size, aneurysm condition (ruptured or unruptured), packing ratio and thromboembolic complication were reviewed. The location of aneurysm was classified into three titles according to Chen's modified classification $^{3)}$ : group I (supra-ophthalmic), group II (ophthalmic), and group III (infra-ophthalmic). Group I consisted of aneurysm with necks arising from the supra-ophthalmic segment of the ICA. Group II included true ophthalmic aneurysm with necks arising from the junction of the ophthalmic artery and the ICA. Group III aneurysm was located between the origin of the ophthalmic artery and the proximal dural ring.

Supra-ophthalmic segment aneurysms were further classified according to the classification established by Day and Barami $^{1,5,28)}$. Subtype I aneurysms arose from ICA distal to the ophthalmic artery and had superior or supero-medial direction. Subtype II aneurysms presented from the ventral, medial, or lateral segment of the supra-ophthalmic ICA, and were not in contact with the ophthalmic artery.

The projection of the aneurysm was divided into a medial, lateral, superior and inferior projection based on the dominant orientation of the aneurysm. The medially directing aneurysms, which occupied the largest portion according to this classification, were termed 'medial projection aneurysms' and separately investigated in order to reduce the heterogeneity of the study objects concerning aneurysm direction.

We measured the aneurysm geometry and calculated the dome-to-neck ratio and aneurysm volume in pre-embolization angiograms using aneurysm calculator program (Angiocalc, Charlottesville, VA, USA). After embolization, the coil packing density ratio was calculated using the same program. Each patient's treatment result was confirmed by digital subtraction angiography after embolization. Treatment results were classified as complete occlusion, neck remnants, and sac remnants according to the Raymond-Roy Classification ${ }^{24)}$.

Recurrence and progressive occlusion were assessed based on the Raymond-Roy Classification of the follow-up images by digital subtraction angiography or MR angiography. Recurrence was defined as more than one grade worsening in the follow-up study compared to the immediate post-operative results, i.e., from complete occlusion to remnant neck or to remnant sac, or from remnant neck to remnant sac. Major recanalization which remnant aneurysm was aggravated to be 
large enough to permit retreatment was included recurrence category. Stable remnant neck-lesions, remnant sac lesions without coil compaction or aneurysmal growth, and minor recanalization that did not require retreatment were omitted from the recurrence category. Progressive occlusion was defined as more than one grade improvement in the follow-up study, i.e., from remnant sac to remnant neck or complete occlusion, or from remnant neck to complete occlusion.

Thromboembolic complication was defined as the angiographic filling defect due to the thrombus that occurred in the parent artery of the distal branches in any moment during the procedure.

\section{Coiling procedure}

All coiling procedures were performed under general anesthesia. In unruptured aneurysms, dual antiplatelets (100 mg of aspirin and $75 \mathrm{mg}$ of clopidogrel) were started two weeks before the treatment to prevent thromboembolic complication. During the embolization procedure, activated coagulation time (ACT) was checked every hour and intravenous heparin was injected to maintain ACT level between 250 and 300. In ruptured cases, intravenous heparin was administered only when there was a high probability of thromboembolic complication during the procedure. Dual antiplatelets (aspirin $100 \mathrm{mg}$ and clopidogrel $75 \mathrm{mg}$ ) were prescribed for at least one year after the stent-assisted procedure, and aspirin was maintained thereafter in some patients.

\section{Statistical analysis}

The statistical analysis was generated using the SPSS version 24 (IBM Corp., Armonk, NY, USA). Comparisons of the data were assessed by the Independent t-test and Chi-square test (Fisher's exact test). For all analyses, $p$-value of less than 0.05 was considered statistically significant.

We used multivariate logistic regression model to verify the variables with recurrence and progressive occlusion. The criteria for the adjustment were a $p$-value of less than 0.2 from Chi-square test. However, sex was excluded from multivariate logistic regression analysis because it was identified as an inappropriate variable for the adjustment.

\section{RESULTS}

Ninety-eight paraclinoid aneurysms were enrolled in this study treated by endovascular treatment for 11 years. Thirtyseven aneurysms were included in the stent-assisted group and 61 lesions in the simple coiling group. The demographics of the aneurysms are shown in Table 1. Age, sex, aneurysm size, aneurysm volume, projection, packing ratio, immediate angiographic results, thromboembolic complication, mean follow up period, and minor recanalization rate showed no significant differences between the two groups.

The mean neck sizes were $4.6 \pm 2.4 \mathrm{~mm}$ and $3.7 \pm 1.5 \mathrm{~mm}$, in the stent-assisted and simple coiling groups respectively ( $p=0.036$ ). Aneurysms with dome to neck ratios equal to or smaller than 2 occupied 34 out of 37 (94.6\%) in the stent-assisted group, and 43 out of 61 (70.5\%) in the simple coiling group ( $p=0.004)$. These differences were statistically significant. The number of patients with subarachnoid hemorrhages due to ruptured aneurysms was found to be one out of 37 $(2.7 \%)$ in the stent-assisted group and 12 out of 61 (19.6\%) in the simple coiling group, and the difference was statistically significant ( $p=0.016$ ). Concerning location, there was a higher proportion of aneurysms treated with stent-assisted technique in the ophthalmic segment aneurysms compared to coil embolization without stents $(p=0.011)$. In the supra-ophthalmic segment, the rate of subtype I aneurysms treated with stent augmentation were higher than that of subtype II ( $p=0.021$, Table 2).

\section{Long term outcome}

\section{Aneurysm recurrence}

The mean follow-up period was $32.3 \pm 22.4$ months in the stent-assisted group and $34.2 \pm 28.5$ months in the simple coiling group ( $p=0.722$, Table 1 ). Aneurysm recurrence was found in only one out of 37 patients $(2.7 \%)$ in the stent-assisted group and 13 out of $61(21.3 \%)$ in the simple coiling group $(p=0.011$, Tables 1 and 3). As shown in Table 3, the recurrence rate according to the age, sex, packing ratio, ruptured/unruptured condition, aneurysm location and projection of aneurysm were not statistically significant. Multivariate logistic regression model showed substantially the lower recurrence rate in the stent-assisted group when adjusted for the aneurysm size, neck size, dome to neck ratio and aneurysm volume (odds ra- 
Stent-Assisted Embolization in Paraclinoid Aneurysms | Kim SY, et al.

Table 1. Demographics

\begin{tabular}{|c|c|c|c|}
\hline Variable & Stent-assisted & Simple coiling & $p$-value \\
\hline No. of aneurysms & 37 & 61 & \\
\hline Mean age (years) & $52.7 \pm 13.1$ & $55.1 \pm 11.4$ & 0.339 \\
\hline Female gender & $32(86.5)$ & $51(83.6)$ & \\
\hline Aneurysm size (mm) & $5.3 \pm 4.7$ & $6.1 \pm 3.7$ & 0.337 \\
\hline Neck size (mm) & $4.6 \pm 2.4$ & $3.7 \pm 1.5$ & 0.036 \\
\hline Dome to neck ratio, 2 or less & $35(94.6)$ & $43(70.5)$ & 0.004 \\
\hline Aneurysm volume (mL) & $0.28 \pm 0.75$ & $0.16 \pm 0.26$ & 0.363 \\
\hline Packing ratio (\%) & $24.3 \pm 8.2$ & $26.6 \pm 14.1$ & 0.331 \\
\hline Aneurysm condition, ruptured & $1(2.7)$ & $12(19.6)$ & 0.016 \\
\hline \multicolumn{4}{|l|}{ Aneurysm location } \\
\hline Supra-ophthalmic & $17(45.9)$ & $30(49.2)$ & 0.460 \\
\hline Ophthalmic & $6(16.2)$ & $1(1.6)$ & 0.011 \\
\hline Infra-ophthalmic & $14(37.9)$ & $30(49.2)$ & 0.302 \\
\hline Immediate angiographic results & & & 0.422 \\
\hline Complete occlusion & $8(21.6)$ & $18(29.5)$ & \\
\hline Neck remnant & $14(37.9)$ & $26(42.6)$ & \\
\hline Sac remnant & $15(40.5)$ & $17(27.9)$ & \\
\hline Aneurysm projection & & & 0.180 \\
\hline Medial & $14(37.9)$ & $35(57.4)$ & \\
\hline Lateral & $5(13.5)$ & $4(6.5)$ & \\
\hline Superior & $11(29.7)$ & $10(16.4)$ & \\
\hline Inferior & $7(18.9)$ & $12(19.7)$ & \\
\hline Thromboembolic complication & $1(2.7)$ & $0(0)$ & 0.378 \\
\hline Mean F/U period (months) & $32.3 \pm 22.4$ & $34.2 \pm 28.5$ & 0.722 \\
\hline Recurrence & $1(2.7)$ & $13(21.3)$ & 0.011 \\
\hline Minor recanalization & $2(5.4)$ & $10(16)$ & 0.126 \\
\hline Progressive occlusion* & $16(55.2)$ & $10(23.3)$ & 0.006 \\
\hline
\end{tabular}

Values are presented as mean \pm standard deviation or number (\%). ${ }^{*}$ Complete occlusion was excluded. F/U : follow-up

Table 2. Relationship between direction of supra-ophthalmic segment and stent placement

\begin{tabular}{lccc}
\hline Subtype & Stent-assisted & Simple coiling & $p$-value \\
\hline Subtype $I^{*}$ & $11(55)$ & $9(45)$ & 0.021 \\
${\text { Subtype } I^{\dagger}}^{\text {Sal }}$ & $6(22.2)$ & $21(77.8)$ & \\
\hline
\end{tabular}

Values are presented as number (\%). *Subtype I : superior or supero-medial direction. 'Subtype II : ventral, medial, or lateral direction

tio $[\mathrm{OR}]$ 0.051, 95\% confidence interval [CI] 0.005-0.527).

\section{Progressive occlusion}

Progressive occlusion was found in 16 out of 29 patients $(55.2 \%)$ in the stent-assisted group and 10 out of 43 patients (23.3\%) in the simple coiling group ( $p=0.006$, Tables 1 and 4 ). Multivariate logistic regression model showed a higher progressive occlusion rate in the stent-assisted group when ad- justed for packing ratio and ruptured/unruptured condition (OR 3.208, 95\% CI 1.106-9.302).

\section{Medial projection aneurysms}

Among the medial projection aneurysms, 14 patients were treated using stents and 35 patients using only coils. Most of factors were not significantly different between the two groups. The 
Table 3. Recurrence associated with variables

\begin{tabular}{|c|c|c|c|c|c|c|}
\hline \multirow{2}{*}{ Variable } & \multirow{2}{*}{ Recurrence } & \multirow{2}{*}{ No recurrence } & \multirow{2}{*}{$p$-value } & \multicolumn{3}{|c|}{ Multivariate analysis } \\
\hline & & & & OR & $95 \% \mathrm{Cl}$ & $p$-value \\
\hline $\operatorname{Sex}(M: F)$ & $0: 14$ & $15: 69$ & 0.117 & - & - & - \\
\hline \multicolumn{7}{|l|}{ Age (years) } \\
\hline$\geq 55:<55$ & $7: 7$ & $46: 38$ & 0.741 & - & - & - \\
\hline \multicolumn{7}{|l|}{ Aneurysm size (mm) } \\
\hline$\geq 7:<7$ & $9: 5$ & $16: 68$ & 0.001 & 9.989 & $2.089-47.773$ & 0.004 \\
\hline \multicolumn{7}{|l|}{ Neck size (mm) } \\
\hline$\geq 4:<4$ & $11: 3$ & $27: 57$ & 0.001 & 2.858 & $0.185-44.072$ & 0.452 \\
\hline \multicolumn{7}{|l|}{ Dome to neck ratio } \\
\hline$>2: \leq 2$ & $6: 8$ & $14: 70$ & 0.035 & 0.924 & $0.160-5.354$ & 0.930 \\
\hline \multicolumn{7}{|l|}{ Aneurysm volume (mL) } \\
\hline$\geq 0.2:<0.2$ & $8: 6$ & $11: 73$ & 0.001 & 2.582 & $0.181-36.802$ & 0.484 \\
\hline \multicolumn{7}{|l|}{ Packing ratio (\%) } \\
\hline$\geq 20:<20$ & $7: 7$ & $55: 29$ & 0.233 & - & - & - \\
\hline \multicolumn{7}{|l|}{ Aneurysm condition } \\
\hline Ruptured : unruptured & $3: 11$ & $10: 74$ & 0.391 & - & - & - \\
\hline Aneurysm location & & & 0.528 & - & - & - \\
\hline Supra-ophthalmic & 7 & 40 & & & & \\
\hline Ophthalmic & 0 & 7 & & & & \\
\hline Infra-ophthalmic & 7 & 37 & & & & \\
\hline Aneurysm projection & & & 0.351 & - & - & - \\
\hline Medial & 7 & 42 & & & & \\
\hline Lateral & 3 & 6 & & & & \\
\hline Superior & 2 & 19 & & & & \\
\hline Inferior & 2 & 17 & & & & \\
\hline \multicolumn{7}{|l|}{ Stent placement } \\
\hline Stent-assisted : simple coiling & $1: 13$ & $36: 48$ & 0.011 & 0.051 & $0.005-0.527$ & 0.012 \\
\hline
\end{tabular}

$\mathrm{OR}$ : odds ratio, $\mathrm{Cl}$ : confidence interval, $\mathrm{M}$ : male, $\mathrm{F}$ : female

ruptured aneurysms accounted for zero out of 14 patients $(0 \%)$ in the stent-assisted group and 9 out of 35 patients (25.7\%) in the simple coiling group $(p=0.045)$. Aneurysms with dome to neck ratios equal to or smaller than 2 , occupied higher proportion in the stent-assisted group than in the simple coiling group ( $p=0.011$, Table 5). Table 6 shows that the recurred group has a lower mean packing ratio than the group without recurrence $(p=0.005)$.

\section{DISCUSSION}

Endovascular treatment of intracranial aneurysms has be- come increasingly important, with advances in the neurointervention and endovascular techniques ${ }^{23,29)}$. Particularly, coil embolization is the main treatment for paraclinoid aneurysms due to its anatomical specificity. However, aneurysm recurrence is a matter of concern when deciding endovascular treatment and efforts have been made to lower this recurrence. Aneurysmal recurrence rate has been reported to be around $10-33.6 \%$ according to previously published reports. Larger aneurysm size, ruptured aneurysms, anterior circulation aneurysms, incomplete embolization and underlying hypertension have been considered as factors that increase the recurrence rate of aneurysm after endovascular treatment ${ }^{15,29)}$. 
Stent-Assisted Embolization in Paraclinoid Aneurysms | Kim SY, et al.

Table 4. Progressive occlusion associated with variables

\begin{tabular}{|c|c|c|c|c|c|c|}
\hline \multirow{2}{*}{ Variable } & \multirow{2}{*}{ Recurrence } & \multirow{2}{*}{ No recurrence } & \multirow{2}{*}{$p$-value } & \multicolumn{3}{|c|}{ Multivariate analysis } \\
\hline & & & & OR & $95 \% \mathrm{Cl}$ & $p$-value \\
\hline $\operatorname{Sex}(M: F)$ & $5: 21$ & $4: 42$ & 0.269 & - & - & - \\
\hline \multicolumn{7}{|l|}{ Age (years) } \\
\hline$\geq 55:<55$ & $14: 12$ & $25: 21$ & 0.967 & - & - & - \\
\hline \multicolumn{7}{|l|}{ Aneurysm size (mm) } \\
\hline$\geq 7:<7$ & $5: 21$ & $15: 31$ & 0.223 & - & - & - \\
\hline \multicolumn{7}{|l|}{ Neck size (mm) } \\
\hline$\geq 4:<4$ & $9: 17$ & $21: 25$ & 0.362 & - & - & - \\
\hline \multicolumn{7}{|l|}{ Dome to neck ratio } \\
\hline$>2: \leq 2$ & $4: 22$ & $13: 33$ & 0.217 & - & - & - \\
\hline \multicolumn{7}{|l|}{ Aneurysm volume (mL) } \\
\hline$\geq 0.2:<0.2$ & $3: 23$ & $11: 35$ & 0.203 & - & - & - \\
\hline \multicolumn{7}{|l|}{ Packing ratio (\%) } \\
\hline$\geq 20:<20$ & $18: 8$ & $25: 21$ & 0.176 & 1.999 & $0.659-6.063$ & 0.221 \\
\hline \multicolumn{7}{|l|}{ Aneurysm condition } \\
\hline Ruptured : unruptured & $1: 25$ & $8: 38$ & 0.143 & 0.294 & $0.033-2.632$ & 0.274 \\
\hline Aneurysm location & & & 0.865 & - & - & - \\
\hline Supra-ophthalmic & 12 & 22 & & & & \\
\hline Ophthalmic & 1 & 3 & & & & \\
\hline Infra-ophthalmic & 13 & 21 & & & & \\
\hline Aneurysm projection & & & 0.398 & - & - & - \\
\hline Medial & 10 & 27 & & & & \\
\hline Lateral & 3 & 4 & & & & \\
\hline Superior & 8 & 8 & & & & \\
\hline Inferior & 5 & 7 & & & & \\
\hline \multicolumn{7}{|l|}{ Stent placement } \\
\hline Stent-assisted : simple coiling & $16: 10$ & $13: 33$ & 0.006 & 3.208 & $1.106-9.302$ & 0.032 \\
\hline
\end{tabular}

Complete occlusion was excluded. OR : odds ratio, $\mathrm{Cl}$ : confidence interval, $\mathrm{M}$ : male, $\mathrm{F}$ : female

At the same time, lack of stent assistance has also been shown to play a role in increasing the recurrence rate ${ }^{4,29)}$.

In our study, the stent-assisted group had a lower recurrence rate than the simple coiling group. Stent-assisted group had higher mean aneurysm volume, lower mean packing ratio, and poorer immediate angiographic results compared to the simple coiling group, which may increase the recurrence rate. Despite these factors which are known to contribute to aneurysmal recurrence, the stent-assisted group showed a markedly lower recurrence rate than the simple coiling group.

There was no significant correlation between recurrence rates depending on the projection of aneurysm in our study. Oh et al. ${ }^{19)}$ reported that superiorly located paraclinoid aneu- rysms appear more likely to rupture than other locations in an analysis of 265 paraclinoid aneurysms. Lee et al. ${ }^{12)}$ reported rupture in four out of eight dorsal wall aneurysms which showed rapid growth and configurational change. In paraclinoid aneurysms, the hemodynamic stress is thought to be higher in the anterior-superior wall of the paraclinoid ICA compared to other directions. The hemodynamic stress on the superior wall may be a common causative factor for aneurysmal growth and rupture ${ }^{17)}$. In our study, the recurrence rate did not show a significant difference according to the projection of the aneurysm, presumably because the stent-assisted coil embolization was more frequently performed in the superiorly projecting subtype I group than the subtype II group. 
J Korean Neurosurg Soc 60 | November 2017

Table 5. Demographics of medial projection aneurysms

\begin{tabular}{|c|c|c|c|}
\hline Variable & Stent-assisted & Simple coiling & $p$-value \\
\hline No. of aneurysms & 14 & 35 & \\
\hline Mean age (years) & $53.0 \pm 14.7$ & $52.9 \pm 10.4$ & 0.969 \\
\hline Female gender & $12(85.7)$ & $29(82.9)$ & \\
\hline Aneurysm size (mm) & $5.8 \pm 5.6$ & $5.9 \pm 2.7$ & 0.915 \\
\hline Neck size (mm) & $4.9 \pm 3.2$ & $3.5 \pm 1.3$ & 0.146 \\
\hline Dome to neck ratio, 2 or less & $14(100)$ & $23(65.7)$ & 0.011 \\
\hline Aneurysm volume (mL) & $0.27 \pm 0.65$ & $0.16 \pm 0.19$ & 0.508 \\
\hline Packing ratio (\%) & $24.8 \pm 9.5$ & $25.8 \pm 13.7$ & 0.802 \\
\hline Aneurysm condition, ruptured & $0(0)$ & $9(25.7)$ & 0.045 \\
\hline Immediate angiographic results & & & 0.254 \\
\hline Complete occlusion & $5(35.7)$ & $7(20.0)$ & \\
\hline Neck remnant & $4(28.6)$ & $19(54.3)$ & \\
\hline Sac remnant & $5(35.7)$ & $9(25.7)$ & \\
\hline Thromboembolic complication & $1(7.1)$ & 0 & 0.286 \\
\hline Mean F/U period (months) & $37.1 \pm 26.2$ & $31.5 \pm 28.4$ & 0.531 \\
\hline Recurrence & $1(7.1)$ & $6(17.1)$ & 0.656 \\
\hline Progressive occlusion & $5(35.7)$ & $5(14.3)$ & 0.124 \\
\hline
\end{tabular}

Values are presented as mean \pm standard deviation or number (\%). F/U : follow-up

Table 6. Recurrence associated with variables of medial projection aneurysms

\begin{tabular}{|c|c|c|c|}
\hline Variable & Recurrence $(n=7)$ & No recurrence $(n=42)$ & $p$-value \\
\hline Aneurysm size (mm) & $9.7 \pm 5.3$ & $5.2 \pm 3.0$ & 0.069 \\
\hline Neck size (mm) & $5.1 \pm 2.4$ & $3.7 \pm 2.0$ & 0.109 \\
\hline Dome to neck ratio & $1.8 \pm 0.4$ & $1.5 \pm 0.5$ & 0.138 \\
\hline Packing ratio (\%) & $19.4 \pm 3.2$ & $26.5 \pm 13.2$ & 0.005 \\
\hline Aneurysm volume (mL) & $0.56 \pm 0.75$ & $0.13 \pm 0.23$ & 0.175 \\
\hline Aneurysm condition, ruptured & $2(28.6)$ & $7(16.7)$ & 0.598 \\
\hline Aneurysm location & & & 0.551 \\
\hline Supra-opthalmic & $4(57.1)$ & $16(38.1)$ & \\
\hline Opthalmic & $0(0)$ & $3(7.1)$ & \\
\hline Infra-opthalmic & $3(42.9)$ & $23(54.8)$ & \\
\hline
\end{tabular}

Values are presented as mean \pm standard deviation or number (\%)

We thought that stent placement may have reduced the recurrence rate by diverting the flow into the aneurysm and thereby minimizing the hemodynamic stress.

In our study, more stent augmentation was done in unruptured aneurysms, ophthalmic artery aneurysms, and widenecked aneurysms (dome to neck ratio 2 or less) with statistical significance. Sufficient time margin and minimization of thromboembolic risk by preoperative antiplatelet therapy may have allowed a more safe and stable stent-assisted coil emboli- zation procedure in the treatment of unruptured aneurysms when compared to ruptured aneurysms which is usually an emergency situation requiring short operative time and risk of heparinization surpassing its benefit.

In the treatment of the wide-necked aneurysms, the coil mass is usually unstable within the aneurysms, especially at the neck, and is likely to prolapse into the parent artery. The aneurysm is easily affected by hemodynamic flow of the parent artery during the coiling procedure because of the large 
cross-sectional area exposed to the parent artery. In such cases, stent placement may prevent coil mass herniation into the parent artery and allow dense packing of the aneurysm with coils $^{6,7,21,30)}$.

In addition to these structural aspects, stent placement can induce hemodynamic changes within the aneurysm through flow diversion, promoting delayed thrombosis, and providing the basis for endothelialzation ${ }^{4,8,11,20)}$. Such processes may aid in achieving progressive occlusion in the long term. In particular, stent placement may lower the recurrence by reducing the flow velocity of the neck plane compared with residual neck or dome in subtotally occluded paraclinoid aneurysms ${ }^{14)}$.

Concerning the packing ratio and aneurysmal recurrence, our study did not prove a direct relationship between the two factors. This result was not concordant with previous reports which suggested that higher packing ratio above could lower recurrence rates ${ }^{1325)}$. They mentioned that insufficient coil packing increases the possibility of aneurysm wall exposure to blood flow. Loosely packed coil is also prone to coil compaction, which is another mechanism of aneurysm recurrence ${ }^{9,10,16,27)}$. We presume that our study showed a different result because the above mentioned effect of stent placement may have affected and masked the effect of higher packing ratio leading to progressive intra-aneurysmal thrombosis. Small study sample and heterogeneity of the group may also have affected the result. However, in a subgroup analysis processed with only medially projecting aneurysms, the group that showed recurrence had a lower mean packing ratio than the group without recurrence.

Thromboembolic complication is a major limitation concerning endovascular treatment. Yang et al. ${ }^{29)}$ reported on the thromboembolic complications among 563 patients who underwent endovascular treatment. They stressed that there was no significant difference in the thromboembolic complications between the stent-assisted group (13 out of 269 patients, $4.8 \%$ ) and simple coiling group (10 out of 243 patients, $4.1 \%$ ). In an analysis of 70 patients treated with stent-assisted coiling of paraclinoid aneurysm by Ogilvy et al. ${ }^{18)}$, thromboembolic events occurred in two out of 70 patients (2.86\%). Colby et al. ${ }^{4}$ reported $0 \%$ and $3.3 \%$ of thromboembolic complication in the stent-assisted group and simple coiling group, respectively, in their study on endovascular treatment of 90 paraophthalmic region aneurysms. In our study, progressive dissolution of thrombus was observed after the intra-arterial infusion of 0.5 mg of Tirofiban in one case of thromboembolic complication. There was no postoperative neurologic deficit.

Generally, stent-assisted coil embolization is considered to increase the chance of thromboembolic complication because of the longer procedure time, more likeliness of vessel wall injury by stiffer devices and sharp stent lumen, and introduction of closely packed scaffolds within the vessel lumen. However, our study, along with the previous reports, showed that the stent-assisted group did not significantly increase thromboembolic complication compared to the simple coiling group. This may be due to premedication with antiplatelets, anticoagulation with heparin during the procedure and the development of the new, safer endovascular devices resulting in less vessel wall damage, easier handling and shortened procedure time. Therefore, concern on thromboembolic complication does not seem to surpass the advantages of stent placement in wide-necked paraclinoid aneurysms that are uneasy to treat without stents.

\section{Limitation}

There were several limitations in our study. Firstly, the two groups were not matched; they differed in their pre-operative conditions and aneurysm location. There were more ruptured cases in the simple coiling group compared to the stent-assisted group. The ophthalmic artery aneurysms were more frequently treated using stents than other locations. This may have affected the final radiological outcomes. Secondly, two operators were involved in the embolization of aneurysms. They were not blinded, and their selection of devices and styles of procedure may have differed. Thirdly, this study was conducted retrospectively and the data extracted from the medical charts were initially recorded for clinical necessity rather than for research purposes.

In spite of the mentioned limitations, however, the results of our study highlight a strong relationship between stent placement and reduced recurrence rate, which can be referred to when treating paraclinoid aneurysms.

\section{CONCLUSION}

In our study, the stent-assisted group was related to a lower recurrence rate and a higher progressive occlusion rate compared to the simple coiling group in endovascular treatment 
of paraclinoid aneurysms. Therefore, stent-assisted coil embolization can be said to be an effective treatment strategy for widenecked paraclinoid aneurysms. However, routine use of stents is unreasonable given higher cost, prolonged procedure time, and necessity of post-operative antiplatelet administration.

\section{References}

1. Barami K, Hernandez VS, Diaz FG, Guthikonda M : Paraclinoid carotid aneurysms: surgical management, complications, and outcome based on a new classification scheme. Skull Base $13:$ 31-41, 2003

2. Chalouhi N, Jabbour P, Singhal S, Drueding R, Starke RM, Dalyai RT, et al. : Stent-assisted coiling of intracranial aneurysms: predictors of complications, recanalization, and outcome in 508 cases. Stroke 44 : 13481353, 2013

3. Chen L, Kato Y, Karagiozov KL, Yoneda M, Imizu S, Hayakawa M, et al. : Usefulness of a simplified management scheme for paraclinoid aneurysms based on a modified classification. Cerebrovasc Dis 26 : 388396, 2008

4. Colby GP, Paul AR, Radvany MG, Gandhi D, Gailloud P, Huang J, et al. : A single center comparison of coiling versus stent assisted coiling in 90 consecutive paraophthalmic region aneurysms. J Neurointerv Surg 4 : 116-120, 2012

5. Day AL : Aneurysms of the ophthalmic segment. A clinical and anatomical analysis. J Neurosurg 72 : 677-691, 1990

6. Durst CR, Khan P, Gaughen J, Patrie J, Starke RM, Conant P, et al. : Direct comparison of Neuroform and Enterprise stents in the treatment of wide-necked intracranial aneurysms. Clin Radio 69 : e471-e476, 2014

7. Hwang SK, Hwang G, Bang JS, Oh CW, Kwon OK : Endovascular Enterprise stent-assisted coil embolization for wide-necked unruptured intracranial aneurysms. J Clin Neurosci 20 : 1276-1279, 2013

8. Jahshan S, Abla AA, Natarajan SK, Drummond PS, Kan P, Karmon Y, et al. : Results of stent-assisted vs non-stent-assisted endovascular therapies in 489 cerebral aneurysms: single-center experience. Neurosurgery $72:$ 232-239, 2013

9. Kai Y, Hamada J, Morioka M, Yano S, Kuratsu J : Evaluation of the stability of small ruptured aneurysms with a small neck after embolization with Guglielmi detachable coils: correlation between coil packing ratio and coil compaction. Neurosurgery 56 : 785-792; discussion 785792, 2005

10. Kawanabe Y, Sadato A, Taki W, Hashimoto N : Endovascular occlusion of intracranial aneurysms with Guglielmi detachable coils: correlation between coil packing density and coil compaction. Acta Neurochir (Wien) $143:$ 451-455, 2001

11. Lawson MF, Newman WC, Chi YY, Mocco JD, Hoh BL : Stent-associated flow remodeling causes further occlusion of incompletely coiled aneurysms. Neurosurgery 69 : 598-603; discussion 603-604, 2011

12. Lee CC, Hsieh TC, Wang YC, Lo YL, Lee ST, Yang TC : Ruptured symp- tomatic internal carotid artery dorsal wall aneurysm with rapid configurational change. Clinical experience and management outcome: an original article. Eur J Neurol 17 : 1277-1284, 2010

13. Leng $B$, Zheng $Y$, Ren J, Xu Q, Tian $Y, X u F$ : Endovascular treatment of intracranial aneurysms with detachable coils: correlation between aneurysm volume, packing, and angiographic recurrence. J Neurointerv Surg 6 : 595-599, 2014

14. Liu J, Jing L, Wang C, Paliwal N, Wang S, Zhang Y, et al. : Effect of hemodynamics on outcome of subtotally occluded paraclinoid aneurysms after stent-assisted coil embolization. J Neurointerv Surg 8 : 11401147, 2016

15. Lv N, Zhao R, Yang $P$, Fang $Y, L i ~ Q, X u Y$, et al. : Predictors of recurrence after stent-assisted coil embolization of paraclinoid aneurysms. J Clin Neurosci 33 : 173-176, 2016

16. Ng P, Khangure MS, Phatouros CC, Bynevelt M, ApSimon H, McAuliffe $W$ : Endovascular treatment of intracranial aneurysms with Guglielmi detachable coils: analysis of midterm angiographic and clinical outcomes. Stroke $33: 210-217,2002$

17. Ogawa A, Suzuki M, Ogasawara K : Aneurysms at nonbranching sites in the surpaclinoid portion of the internal carotid artery: internal carotid artery trunk aneurysms. Neurosurgery 47 : 578-583; discussion 583586, 2000

18. Ogilvy CS, Natarajan SK, Jahshan S, Karmon Y, Yang X, Snyder KV, et al. Stent-assisted coiling of paraclinoid aneurysms: risks and effectiveness. J Neurointerv Surg 3 : 14-20, 2011

19. Oh SY, Kim MJ, Kim BM, Lee KS, Kim BS, Shin YS : Angiographic characteristics of ruptured paraclinoid aneurysms: risk factors for rupture. Acta Neurochir (Wien) 155 : 1493-1499, 2013

20. Piotin M, Blanc R, Spelle L, Mounayer C, Piantino R, Schmidt PJ, et al. : Stent-assisted coiling of intracranial aneurysms: clinical and angiographic results in 216 consecutive aneurysms. Stroke 41 : 110-115, 2010

21. Raslan AM, Oztaskin M, Thompson EM, Dogan A, Petersen B, Nesbit $G$, et al. : Neuroform stent-assisted embolization of incidental anterior communicating artery aneurysms: long-term clinical and angiographic follow-up. Neurosurgery 69 : 27-37; discussion 37, 2011

22. Raymond J, Guilbert F, Weill A, Georganos SA, Juravsky L, Lambert A, et al. : Long-term angiographic recurrences after selective endovascular treatment of aneurysms with detachable coils. Stroke 34 : 1398-1403, 2003

23. Ries T, Siemonsen S, Thomalla G, Grzyska U, Zeumer H, Fiehler I : Longterm follow-up of cerebral aneurysms after endovascular therapy prediction and outcome of retreatment. AJNR Am J Neuroradiol 28 : 1755 1761,2007

24. Roy D, Milot G, Raymond J : Endovascular treatment of unruptured aneurysms. Stroke 32 : 1998-2004, 2001

25. Sluzewski M, van Rooij WJ, Slob MJ, Bescós JO, Slump CH, Wijnalda D : Relation between aneurysm volume, packing, and compaction in 145 cerebral aneurysms treated with coils. Radiology 231 : 653-658, 2004

26. Sorimachi T, Ito $Y$, Morita $K$, Jimbo $Y$, Nishino $K$, Sasaki O, et al. : Longterm follow-up of intra-aneurysmal coil embolization for unruptured paraclinoid aneurysms. Neurol Res 34 : 864-870, 2012 
Stent-Assisted Embolization in Paraclinoid Aneurysms | Kim SY, et al.

27. Thornton J, Debrun GM, Aletich VA, Bashir Q, Charbel FT, Ausman J : Follow-up angiography of intracranial aneurysms treated with endovascular placement of Guglielmi detachable coils. Neurosurgery 50 : 239-249; discussion 249-250, 2002

28. Wang Y, Li Y, Jiang C, Wu Z, Jiang F, Meng H, et al. : Could the types of paraclinoid aneurysm be used as a criterion in choosing endovascular treatment? Neuro-radiologists' view. Acta Neurochir (Wien) 155 : 2019-2027, 2013
29. Yang H, Sun Y, Jiang Y, Lv X, Zhao Y, Li Y, et al. : Comparison of stentassisted coiling vs coiling alone in 563 intracranial aneurysms: safety and efficacy at a high-volume center. Neurosurgery $77: 241-247$ discussion 247, 2015

30. Yun JH, Cho CS : Experiences of neuroform stent applications for ruptured anterior communicating artery aneurysms with small parent vessel. J Korean Neurosurg Soc 48 : 53-58, 2010 